\title{
Impact of Supply Chain Management Strategies on Business Performance
}

\author{
Guna Sekhar Sajja \\ Information Technology \\ University of the Cumberlands \\ Kentucky, USA
}

\begin{abstract}
This study sought to determine the impact of supply chain management (SCM) on the operational performance ofSMEs in United States, with a focus on organizational skills. A study of 300 manufacturing SMEs in the United States that have used SCM methods was performed. Structural equation modeling was used to investigate the connections between the variables. The research indicates that implementing SCM methods enhances company performance and is linked to competences such as R\&D, technology commercialization, manufacturing capacity, and marketing capabilities. As a result, a combination of SCM techniques and organizational skills may help SMEs achieve long-term overall company success. This study findings demonstrate that SCM methods and organizational skills have a substantial impact on overall company success. SCM strategies also have a major impact on SMEs' organizational capabilities. Evaluated the role of organizational skills in moderating the impact of SCM strategy on overall company performance. Higher levels of SCM practices may lead to improved supply chain and company performance, according to this study's findings. It also gives manufacturing company SC managers a multidimensional operational assessment of the construct of SCM for evaluating the comprehensiveness of their companies' SCM operations. This study is one of the first SCM studies on the Jordanian manufacturing sector, focusing on the practices that manufacturing companies in the nation must follow to make their supply chains a viable competitive vehicle for growth. The findings have ramifications for all manufacturers, especially in emerging countries where industrial expansion and the creation of integrated supply chains are critical phases in economic development.
\end{abstract}

\section{Keywords}

Supply Chain Management, Manufacturing firms, Business Performance.

\section{INTRODUCTION}

\subsection{Background to the study}

Small and medium-sized manufacturing firms (SMEs) are improving their operational performance by better managing their supply networks. These businesses are innovating internal processes in order to preserve their competitiveness and long-term viability in an international environment[1]. Because it includes all organizations and activities involved in all processes, from product or service production to consumption, the supply chain is a key factor affecting business performance. The supply chain achieves peak performance by strengthening the links between its businesses to maximize revenues for everyone. Supply chain management (SCM) seeks to improve business performance and competitiveness via these strategic linkages. The success of the supply chain and the business is reliant on the supply chain's strategy being reinforced. Given the significance of SMEs to national economic development, supply chain strategies that guarantee their long-term sustainability must be established and executed[2].

Many methods for dealing with demand and supply have been proposed throughout the supply chain. Examples include ERP (enterprise resource planning), VMI (vendor-managed inventory), CPFR (collaborative planning, forecasting, and replenishment), WMS (warehouse management systems), outsourcing techniques, and organizational skills[3].

When suppliers and distributors cooperate, ownership of commodities is transferred to the distributors when the distributors sell the items to consumers. Supply chain techniques, for example, may enhance information flow between businesses in the chain by decreasing the bullwhip effect, which happens when inventory travels up the chain among organizations farther away from the customer. Furthermore, these approaches may enhance distributorsupplier cooperation, reducing delivery lead times and the occurrence of product shortages.

According to Loury-Okoumba and Mafini[4], inter-firm supply chain techniques have lately been shown to have a positive effect on achieving a common objective in business, ranging from procurement through production, distribution, and sales. Most studies to far, however, have been limited to extrapolating these results to SMEs based on resource-based research on large corporations.

Given the rapid reorganization of America's industrial structure with a focus on high-tech industries such as IT, and diversification, flexibility, and customer-led initiatives as a result of the globalization of corporate logistics, the time has come for a fundamental review of manufacturing companies' SCM strategies, which are based on the heavy and chemical industry-oriented economic growth structure[5].

This study aims to determine the relationship between SCM and business performance in companies that respond most quickly to changes in the industrial and economic environment, proposing a strategic change in the direction of the logistics facility policy for supply and operational performance through an analysis of the relationship between SC and operational performance.

\section{LITERATURE REVIEW}

\subsection{Theoretical review}

The utilized the Supply Chain Strategy. It is difficult to gain a competitive edge in a company only via internal growth. Firms must discover innovative methods to acquire new skills 
in order to adapt and retain their competitiveness as the environment changes and global competition intensifies [6].

Corporate supply chain strategies are important processes that enhance innovation and performance, implying that they may assist companies adapt to environmental changes and improve their development. As a result, an SCM strategy may assist businesses in meeting these issues[7].

Demand and supply planning is an important component of VMI, ERP, CPFR, WMS, and outsourcing strategies, and it has been used in a variety of organizational connections throughout the supply chain. A robust flow of information across inter-firm connections may create a mutually accepted inventory level in terms of VMI [8]. A comprehensive resource management system, in terms of ERP, may be a next-generation business system as well as a collection of apps that allow internal corporate business activities to be presented in a unified manner [3].

Sukati et al. (2012) revealed that ordinary companies may improve supply chain stability by using CPFR technology, stating that CPFR technology can improve SCM performance. Competitive advantage boosts sales in a crowded market with many consumers and suppliers, as the benefits gained via the implementation of CPFR and SCM influence financial return on investment.

Through a study of a third-party logistics service utilized by major American companies, Sabbaghi \& Sabbaghi [10] refer to the decrease of logistical costs, the concentration of key skills, and improved operational efficiency as advantages of logistics outsourcing. As a result, this helps to deduce that the supply chain serves as a catalyst for evoking core strengths and leveraging external logistical knowledge, all while enhancing customer happiness and increasing company efficiency. As a result, this SCM strategy is connected to an integrated information system that allows for clear planning of company-wide resources, and it has a strong connection with the small and medium-sized manufacturing sector, especially in terms of supply chain strategy [5].

\subsection{Organizational Competence}

Supply chain integration competencies relate to key organizational characteristics that may help organizations handle intra- and inter-organizational activities more collaboratively. They boost a company's competitiveness by effectively connecting internal departments to SCM. In the context of the supply chain, many research on organizational skills have been conducted. Internal competences have recently been conceived on three levels: internal integration, supplier integration, and customer integration, according to current research [4].

Organizational skills have a beneficial impact on the operational performance of SMEs. As a result, the purpose of this study is to investigate the connection between internal integration and other factors in more depth by looking at company skills such as $\mathrm{R} \& \mathrm{D}$, technology commercialization, manufacturing, and marketing as organizational competencies [4].

\subsection{Business Operational Performance}

Performance is defined as a company's operational performance, which is primarily evaluated in terms of costs, quality, flexibility, and delivery. According to Asnordin et al. [6], improved organizational skills across supply chain companies, as well as each firm's total operational efficiency, influence performance. Furthermore, companies are focusing on a variety of metrics to better understand how supply chain integration affects performance.

Corporate supply chain integration has a substantial impact on company success. Furthermore, additional research has shown that supply chain integration methods have a substantial impact on operational and development success, as well as an indirect impact on financial performance [5].

According to Lee [7], SCM has an independent and beneficial impact on company performance; however, operational performance is also influenced by operational and financial variables, and the combination of SCM and business performance is anticipated to result in higher sales and profits. As a result, the goal of this research is to quantify these characteristics by including them as dependent variables of total company success.

\subsection{Development of Hypotheses}

Because it is impossible to achieve a competitive edge in all sectors with limited resources, Sukati et al. (2012) argue that companies could replace their lacking skills via different supply chain methods. As a result, they should concentrate on their core competencies for effective management. As previously mentioned, a supply chain strategy is required for businesses to enhance their performance and, as a result, their capabilities. The following hypothesis was developed based on the reasons.

Hypothesis 1: The SCM approach will have a beneficial impact on SMEs' overall performance.

Depending on the organization's capabilities, the supply chain strategy has a direct impact on overall company performance such as quality, pricing, delivery, and flexibility. According to Lee [7], depending on the organization's research, technology commercialization, and marketing skills, supply chain strategies may enhance overall company success. Supply chain strategies may boost corporate success by lowering costs, increasing quality, boosting delivery performance, and offering flexibility by leveraging each company's organizational strengths. As a result, the supply chain serves as a tool for improving company performance. The following hypothesis was developed based on these reasons.

Hypothesis 2: In SMEs, organizational competency has a favorable impact on overall performance.

Environmental unpredictability has an impact on a company's supply chain strategy. According to Asnordin et al. [6], supply chain strategies may help businesses compete by increasing financial performance. Firms can minimize environmental uncertainty and enhance their performance by pursuing supply chain solutions that enable quicker delivery and flexible customer reaction capabilities. Hypothesis 3 is formulated as below;

Hypothesis 3: In SMEs, SCM strategy has a beneficial impact on organizational competency.

Changes in quality, pricing, technical advancement, and crossindustry information transfer are all part of the complexity of a dynamic market environment. Accurate forecasting is tough, putting a lot of strain on businesses. The ability of SMEs to adopt SCM methods is dependent on their organizational capabilities. SCM is dependent on the mediation of internal competences like as $\mathrm{R} \& \mathrm{D}$, technology commercialization, and manufacturing and marketing skills; business success is dependent on the management and systematization of organizational competencies [6], [7]. The following hypothesis was developed based on these reasons. 
Hypothesis 4: In the impact of SCM strategy on overall company performance in SMEs, organizational skills play a mediating function.

\section{METHODOLOGY}

\subsection{Research design}

The current research study adopted a cross-sectional survey research design, which simultaneously observe different study variables. The study further employed the quantitative methodology approach for data collection, analysis, and hypotheses testing. The cross-sectional research design enables the researcher to focus on specific and compelling cases, thereby obtaining a clear understanding of the research problem.

\subsection{Sample Size}

The sample size was established using the sampling techniques of Morgan and Krejcie [12]. The study utilized a sample size of 384 participants.

\subsection{Sampling techniques}

Sampling as a process of obtaining appropriate numbers of persons required to conduct a particular analysis in a manner that represents a relatively more significant population or group of people. Purposive sampling techniques helped to select study participants.

\subsection{Data collection}

As per the recent survey conducted of SCM-focused SMEs in the United States. The study targeted hands-on employees via a mix of e-mail and physical site visits, with each company receiving just one questionnaire. After removing false testimony and missing data, a total of 384 structured selfadministered questionnaires were given, with 300 being utilized for the final analysis. Automobile components, marine engine parts, aviation parts, and heavy equipment parts were the most common industries represented among the

\subsection{Path Analysis}

Table 1 presents the fitness findings of the route analysis. responders. Employees and managers at SMEs were asked to participate in the survey. On a five-point Likert scale, each concept and its indicators are surveyed.

\subsection{Reliability and validity of the study}

Cronbach's alpha was used in the reliability assessment of different multi-item measures in any research study. Content validity for this study was gotten using the Content Validity Coefficient (CVC).

\subsection{Data analysis}

The aim of this study was to establish the empirical effects of supply chain management strategy on the operational and financial performance of SMEs, based on components from previous research. The independent variables are VMI, ERP, CPFR, WMS, and outsourcing; the mediating effect variables are $\mathrm{R} \& \mathrm{D}$, technology commercialization, production, and marketing capabilities, all of which are components of supply chain management and organizational competence; and the dependent variables are operational and financial performance. A structural equation model was utilized to assess these variables using the AMOS program.

\section{RESULTS}

\subsection{Demographic characteristics}

Heavy equipment manufacturers had the greatest frequency in the sample in the industrial sector. Chief executive officers (with the highest response rate) were the most common responders, followed by business executives, deputies, section chiefs, deputy department heads/department heads, or workers. In terms of tenure, 33.7 percent of those polled had worked for the business for five to eight years. In terms of staff count, 36.0 percent of responding businesses had 50 to 100 workers. In terms of revenue, 33.3 percent of the respondents' businesses made between USD 10 billion and USD 20 billion in sales.

Table 1. Fitness of Research Model.

\begin{tabular}{|l|l|l|l|l|l|l|l|}
\hline Classification & GFI & RMR & RMSEA & NFI & CFI & TLI & AGFI \\
\hline Analysis Result & 0.942 & 0.031 & 0.002 & 0.836 & 0.931 & 0.945 & 0.941 \\
\hline Fitness Reference & Value $\geq 0.7$ & $\leq 0.05$ & $\leq 0.05$ & $\geq 0.7$ & $\geq 0.7$ & $\geq 0.7$ & $\geq 0.7$ \\
\hline
\end{tabular}

Note: GFI stands for "goodness of fit index," RMR stands for "root mean square residual," RMSEA stands for "root mean square error of approximation," NFI stands for "normed fit index," CFI stands for "comparative fit index," TLI stands for "Tucker-Lewis index," and AGIF stands for "adjusted goodness of fit index.

According to the fitness index of the model, the value for chisquare was 316.105 , and other values included GFI $=0.942$, RMR $=0.031$, RMSEA $=0.002, \mathrm{NFI}=0.836, \mathrm{CFI}=0.931$, $\mathrm{TLI}=0.941$, and AGFI $=0.987$.

The values for GFI, NFI, AGFI, CFI, and TLI were 0.7 or higher and RMR and RMSEA were 0.05 or lower. This indicates that the fitness of the path analysis for this model was verified.

Table 2 depicts the final route model. SCM strategies and organizational skills were shown to have a substantial impact on the firm's operational and financial success. Furthermore, it was shown that SCM methods have a substantial impact on organizational capabilities. These findings back up hypothesis 1,2 , and 3 . The following are the details.

Table 2. Final Path Analysis

\begin{tabular}{|c|c|c|c|c|c|c|c|c|c|}
\hline & Path & & & B & B & SE & CR & $p$ & $\begin{array}{l}\text { Hypothesis Supported/ } \\
\text { Rejected }\end{array}$ \\
\hline H1-1 & SCM Strategy & $\rightarrow$ & $\begin{array}{c}\text { Business } \\
\text { Performance }\end{array}$ & -0.004 & -0.007 & 0.055 & -0.079 & 0.037 & Supported \\
\hline H1-2 & SCM Strategy & $\rightarrow$ & $\begin{array}{c}\text { Financial } \\
\text { Performance }\end{array}$ & 0.015 & 0.022 & 0.060 & 0.248 & 0.004 & Supported \\
\hline
\end{tabular}




\begin{tabular}{cccccccccc} 
H2-1 & $\begin{array}{c}\text { Organizational } \\
\text { Competence }\end{array}$ & $\rightarrow$ & $\begin{array}{c}\text { Operational } \\
\text { Performance }\end{array}$ & 0.075 & 0.117 & 0.058 & 1.281 & $* * *$ & Supported \\
\hline H2-2 & $\begin{array}{c}\text { Organizational } \\
\text { Competence }\end{array}$ & $\rightarrow$ & $\begin{array}{c}\text { Financial } \\
\text { Performance }\end{array}$ & 0.156 & 0.219 & 0.064 & 2.435 & 0.015 & Supported \\
H3 & SCM Strategy & $\rightarrow$ & $\begin{array}{c}\text { Organizational } \\
\text { Competence }\end{array}$ & 0.574 & 0.595 & 0.061 & 9.456 & $* * *$ & Supported \\
\hline
\end{tabular}

Note: B stands for Regression Weights, SE stands for Standardized Regression Weight, CR is for Critical Ratio, and p stands for Probability *** $p<0.001$.

Hypothesis 1 was accepted based on the path coefficients of $0.007(\mathrm{CR}=0.079, \mathrm{p}=0.037)$ for operational performance and $0.115(\mathrm{CR}=0.248, \mathrm{p}=0.004)$ for financial performance. This was a clear indication that the different SCM strategies have an impact on the performance of a business.

Hypothesis 2 had path coefficients of $0.117(\mathrm{CR}=1.281, \mathrm{p}=$ $0.001)$ for operational performance and $0.219(\mathrm{CR}=2.435, \mathrm{p}$ $=0.015)$ for financial performance, leading to acceptance of hypothesis 2 . This was a clear indication that organizational competence has a positive significant effect on overall business performance.

Hypothesis 3 was accepted based on a path coefficient of $0.574(\mathrm{CR}=9.456, \mathrm{p} 0.001)$. This meant that SCM strategy has a positive influence on organizational competence.

\subsection{Discussion}

As far as relationship between the variablesare concerned, the following are the test results. First, the operational and financial performance of the SMEs examined was significantly influenced by SCM strategies and organizational skills. SCM strategies have had a major impact on the organizational competence of SMEs. This demonstrates that companies who used SCM methods had better organizational skills and operational performance than those that did not. However, improved organizational skills had a mediating role in the underlying reason. Second, organizational competency was shown to have a mediating role in the impact of SCM strategy on operational performance alone, whereas the Hypothesis about its mediating effect on financial performance was found to be false. Firms that used SCM methods had higher organizational skills, but this had no direct impact on their financial success since other variables such as interest rates, oil prices, and the economy influenced their financial performance.

The findings back up Sukati et al. [9]'s assertion that cooperative alliances and connections with supply chain companies, as strategic indicators of SMEs, have a substantial impact on company performance.

Furthermore, Lee [7]'s research vary from this one in that they are industrial studies aimed at improving SCM competence in domestic businesses and identifying industrial and corporate promotion strategies. In particular, Lee [7] conducted a quantitative analysis of various strategic changes and performances in global supply chain companies' growth processes, which sets the direction in which domestic logistics manufacturing firms should change through a comparative evaluation with major domestic logistics companies, and its value is as industrial research to support them in a competitive environment.

This study differs from previous research in that it tried to alter the strategic direction of corporate SCM strategy and network of industries and businesses into consumer-oriented bottom-up logistics development, depending on the changes in the SCM strategy and network of companies and industries.

\section{CONCLUSIONS}

These findings demonstrate that SCM methods including VMI, ERP, CPFR, WMS, and outsourcing have a direct effect on SMEs' operational and financial success. Furthermore, increasing an organization's capabilities, such as R\&D, technology commercialization, manufacturing, and marketing, improves both operational and financial performance. As a result, integrating SCM techniques with organizational skills will improve these manufacturing companies' operational and financial performance. Firms in the supply chain work together as a network of producers and assembly manufacturers to create, distribute, and sell different components and raw materials. As a result, as a strategy to assist SCM, SMEs may enhance their company financial performance by optimizing their organizational competency. In an environment where supply chain rivalry is gaining traction, SMEs may improve their core skills to improve the supply chain's performance and, as a result, their competitiveness. Firms may also find new possibilities by enhancing current supply networks in the near term and researching and creating new supply chains in the long run.

\subsection{Implications of the study}

The importance of expanded integration with external customers and supply partners beyond the research's focus on existing internal in-house customers and supply partners is highlighted in this study, which classifies the factors of supply chain strategy, corporate organizational competence, and operational performance in detail to identify the relationship between them.

It's also important for company management. Manufacturers promoting organizational competency in supply chains should faithfully integrate internal functions before boosting external integration with suppliers and customers, and if they have limited resources in the early stages, manufacturers can maximize the performance of forming supplier and customer integration after completing internal integration.

\subsection{Limitations}

There are several drawbacks to this research. The findings may not be generalizable to other countries or sectors since the sample was limited to the United States and industrial companies. Future research should take this study's methodology and apply it to a variety of nations and sectors.

\section{REFERENCES}

[1] The White House, "Building Resilient Supply Chains,Revitalizing American Manufacturing, and Fostering Braod-based Growth: 100-Day Reviews under Executive Order 14017," pp. 1-250, 2021, [Online]. Available: https://www.whitehouse.gov/briefingroom/statements-releases/2021/06/08/fact-sheet-bidenharris-administration-announces-supply-chain- 
disruptions-task-force-to-address-short-term-supplychain-discontinuities/.

[2] C. R. Arredondo and J. A. Alfaro Tanco, "Supply chain management: Some reflections to improve its influence in business strategy*," Innovar, vol. 31, no. 81, pp. 7-20, 2021, doi: 10.15446/innovar.v31n81.95568.

[3] C. Horne and D. Shillingford, "Supply Chain Resilience Report 2021," p. 72, 2021, [Online]. Available: www.thebci.org.

[4] W. V. Loury-Okoumba and C. Mafini, "Supply chain management antecedents of performance in small to medium scale enterprises," South African J. Econ. Manag. Sci., vol. 24, no. 1, pp. 1-13, 2021, doi: 10.4102/SAJEMS.V24I1.3661.

[5] M. Storer, P. Hyland, M. Ferrer, R. Santa, and A. Griffiths, "Strategic supply chain management factors influencing agribusiness innovation utilization," Int. J. Logist. Manag., vol. 25, no. 3, pp. 487-521, 2014, doi: 10.1108/IJLM-02-2013-0026.

[6] N. A. Asnordin, V. P. K. Sundram, and S. Noranee, "The Influence of Supply Chain Integration Towards Supply
Chain Performance in Manufacturing Firms," Int. J. Acad. Res. Account. Financ. Manag. Sci., vol. 11, no. 1, pp. 1-, 2021, doi: 10.6007/IJARAFMS.

[7] R. Lee, "The effect of supply chain management strategy on operational and financial performance," Sustain., vol. 13, no. 9, 2021, doi: 10.3390/su13095138.

[8] P. Reklitis, D. P. Sakas, P. Trivellas, and G. T. Tsoulfas, "Performance implications of aligning supply chain practices with competitive advantage: Empirical evidence from the agri-food sector," Sustain., vol. 13, no. 16, 2021, doi: 10.3390/su13168734.

[9] I. Sukati, A. B. Hamid, R. Baharun, and R. M. Yusoff, "The Study of Supply Chain Management Strategy and Practices on Supply Chain Performance," Procedia - Soc. Behav. Sci., vol. 40, no. September 2018, pp. 225-233, 2012, doi: 10.1016/j.sbspro.2012.03.185.

[10] N. Sabbaghi and O. Sabbaghi, "Sustainable supply chain management," Pract. Sustain. From Grounded Theory to Emerg. Strateg., no. October, pp. 101-119, 2011, doi: $10.1057 / 9780230116368$. 